\title{
CERAMBYCIDAE (COLEOPTERA) DA COLÔMBIA. I. EBURIINI (CERAMBYCINAE)
}

\author{
Ubirajara R. Martins ${ }^{1,3}$ \\ Maria Helena M. Galileo ${ }^{2,3}$
}

\begin{abstract}
CERAMBYCIDAE (COLEOPTERA) OF COLOMBIA. I. EBURIINI (CERAMBYCINAE). New records added to the Colombian fauna: Susuacanga unicolor (Bates, 1870), Opades costipennis (Buquet, 1844), Eburodacrys havanensis Chevrolat, 1862, E. granipennis Gounelle, 1909, E. moruna Martins, 1997, E. nemorivaga Gounelle, 1909, E. pilicornis Fisher, 1944. New species described: Pantomallus martinezi, from Cundinamarca and Meta and Beraba inermis, from Cundinamarca.
\end{abstract}

KEYWORDS. Cerambycidae, Colombia, Eburiini, new records, new species.

\section{INTRODUÇÃO}

Recentemente, foi publicada uma relação das espécies de Cerambycidae ocorrentes na Colômbia (MARTíneZ, 2000). O estudo de material adicional pertencente ao Instituto de Investigaciones de Recursos Biológicos “Alexander von Humboldt", Villa de Leyva (IAHC) Facultad de Agronomia, Universidad de Colombia, Bogotá (UNAB) e da Coleção Gilberto Mendoza, Santafé de Bogotá (GMIC), enviados por Claudia Martínez, ensejou novos aportes.

Objetiva-se acrescentar novos dados de ocorrências, incluir espécies ainda não assinaladas para a fauna colombiana e descrever novos táxons de Eburiini.

As citações das províncias da Colômbia seguem a ordem adotada por Zanella et al. (2000) e as siglas de coleções são aquelas adotadas por MonNÉ (2001): MZSP, Museu de Zoologia, Universidade de São Paulo.

\section{Susuacanga unicolor (Bates, 1870)}

Eburia unicolor BATES, 1870:265; MonNÉ, 1993:35 (cat.).

Susuacanga unicolor; MARTINs, 1997:60; 1999:140.

Primeiro registro para a Colômbia, esta espécie parece ocupar grande área no país e, na América do Sul, já foi assinalada para a Venezuela, Peru, Brasil (Amazonas até São

1. Museu de Zoologia, Universidade de São Paulo, Caixa Postal 42594, 04299-970 São Paulo SP, Brasil.

2. Museu de Ciências Naturais, Fundação Zoobotânica do Rio Grande do Sul, Caixa Postal 1188, 90001-970, Porto Alegre RS, Brasil.

3. Pesquisador do $\mathrm{CNPq}$ 
Paulo), Bolívia e Paraguai (MARTins, 1999).

Material examinado. COLÔMBIA, Norte de Santander: Arboledas $\left(7^{\circ} 38^{\prime} 46^{\prime \prime N}, 72^{\circ} 48^{\prime} 13^{\prime \prime} \mathrm{W}\right.$, 946m), 9, 13.VIII.1974, Espinosa col. em "palo de cerca, dia soleado" (UNAB); Tolima: Ibagué (4²6’34"N, 75¹4’23"), O', 25.V.1996, H. Castro col. (MZSP).

\section{Opades costipennis (Buquet, 1844)}

Chlorida costipennis Buouet, 1844:221.

Opades costipennis; LaCordaire, 1869:288; Monné, 1993:13 (cat.); Martins, 1999:144.

Opades vittipennis BATES, 1870:261.

Mallocera costifera Waterhouse, 1880:486.

Opades costifera; AuRIVILLIus, 1912:77 (cat.).

Conhecida de Suriname, Guiana Francesa, Brasil (Amapá, Amazonas e Pará) e Equador, registra-se pela primeira vez na Colômbia. A espécie é típica da região da Amazônia e, portanto, ocorrente também na Colômbia amazônica.

Material examinado. COLÔMBIA, Amazonas: PNN (Parque Nacional Natural) Amacayacu Matamata ( $\left.3^{\circ} 23^{\prime} \mathrm{S}, 70^{\circ} 6^{\prime} \mathrm{W}, 150 \mathrm{~m}\right)$,, , 4.VIII-11.IX.2000, A. Parente col. (IAHC).

\section{Pantomallus martinezi sp. nov.}

(Fig. 1)

Etimologia. Epíteto em homenagem a Claudia Martínez (IAHC) por coordenar a remessa de material e pela publicação da lista dos longicórnios da Colômbia.

○. Cabeça avermelhada, revestida por pilosidade amarelada. Lobos oculares superiores com sete fileiras de omatídios. Antenas atingem o ápice dos élitros na base do artículo VIII. Escapo (25x) densamente pontuado e pubescente, enegrecido na face inferior e sem sulco na base. Flagelômeros basais com pilosidade longa. Protórax avermelhado no disco e mais acastanhado para os lados e no prosterno; revestido por pubescência amarelada, densa. Lados do protórax com os tubérculos látero-anteriores e centrais não-enegrecidos. Dois tubérculos pronotais pretos e brilhantes. Élitros avermelhados, pretos ao redor das máculas ebúrneas. Cada um com quatro manchas ebúrneas (fig. 1): duas basais, pequenas, a externa mais longa do que a interna e duas, ao nível do meio, levemente separadas, a interna situada ao nível do terço posterior da interna e com menos da metade do seu comprimento. Costas elitrais moderadamente marcadas entre as máculas e na metade apical, não atingem as extremidades. Pubescência elitral amarelada, densa, permite ver a pontuação que é constituída por pontos finos na metade anterior. Extremidades emarginadas com espinho curto no lado externo. Face ventral do corpo com pubescência amarelada. Pernas amareladas; tarsômeros levemente avermelhados. Abas apicais internas dos meso- e metafêmures, aguçadas.

Q. Antenas alcançam o ápice dos élitros na ponta do antenômero IX. Antenômero III com pêlos menos abundantes do que nos machos. Máculas ebúrneas dos élitros menores; a posterior interna, situa-se no meio da externa. Costas elitrais menos aparentes do que no macho. Tarsômeros amarelados.

Dimensões, em mm, ơ/ / Comprimento total, 22,7/18,4; protórax: comprimento, 3,5/ 3,1, maior largura, 4,7/4,6; comprimento do élitro, 17,1/16,9; largura umeral, 5,9/5,8. 


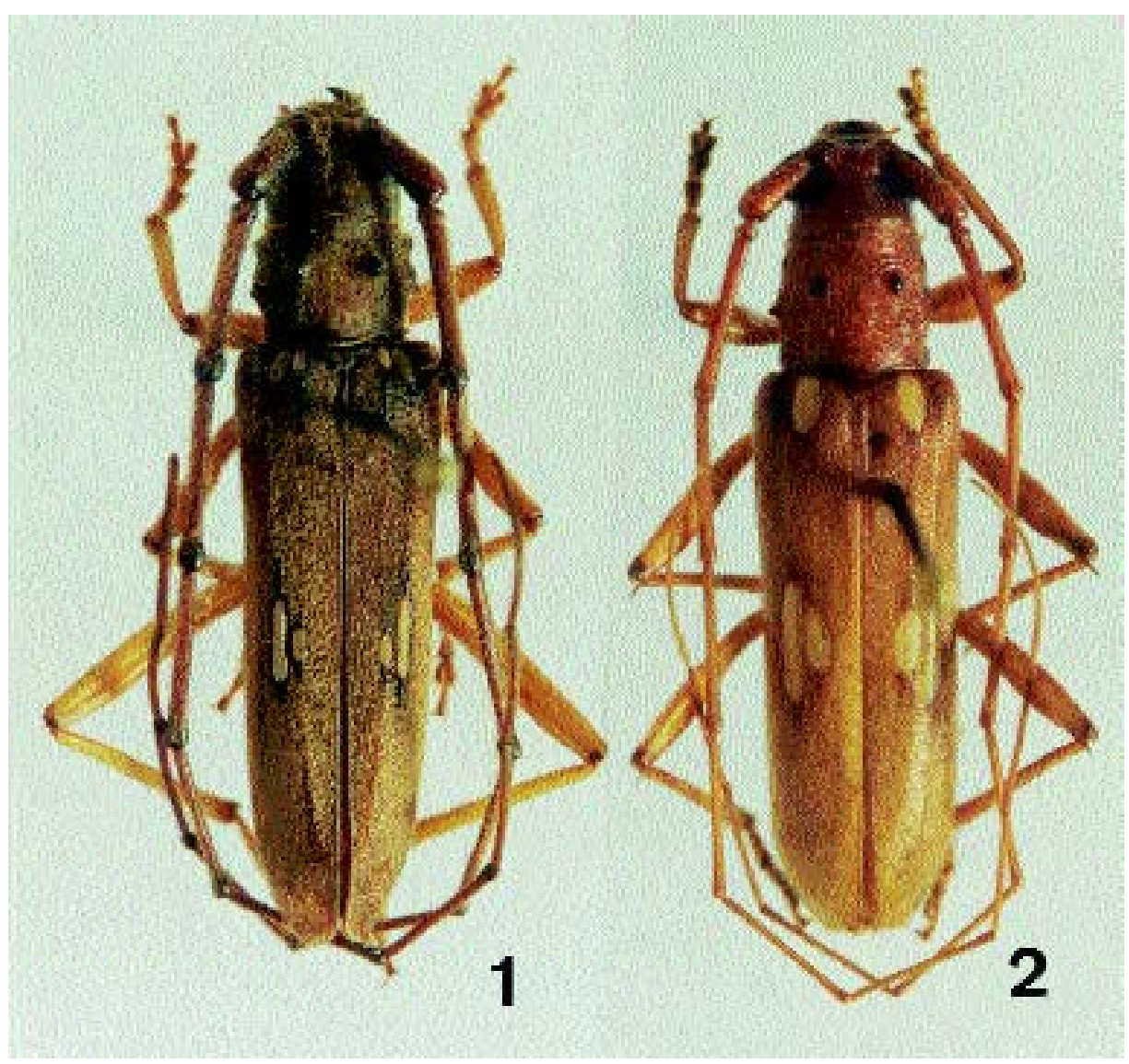

Figs. 1-2. 1, Pantomallus martinezi sp. nov., holótipo ै', comprimento $22,7 \mathrm{~mm} ; 2$, Beraba inermis, sp. nov., holótipo $\widetilde{\sigma}$, comprimento $20,4 \mathrm{~mm}$.

Material-tipo. COLÔMBIA, Cundinamarca: W. Cajicá (Vereda El Canelo), holótipo o', 4.XI.2000, A. Morales \& H. Monroy col. ("se observó volando sobre el cultivo y posándose en las hojas de éste y algunas malezas") (UNAB); Meta: Puerto López $\left(4^{\circ} 06^{\prime} 08^{\prime \prime N}, 72^{\circ} 57^{\prime} 28^{\prime} \mathrm{W}\right)$, parátipo Y, 13.IV.1995, C. Montãnez col. ("perforador tallo") (MZSP).

Discussão. Pantomallus martinezi tem élitros pubescentes, o que a distingue de P. reclusus (Martins, 1981); a pontuação da metade anterior dos élitros não é finíssima e inconspícua, caráter presente em P. proletarius (Erichson, 1847) e P. morosus (AudinetServille, 1834) mas apresenta pontos bem visíveis na metade anterior e não tem costas elitrais para trás das manchas ebúrneas centrais, como em P. pallidus Aurivillius, $1923 \mathrm{e}$ P. costulatus (Bates, 1870). Por estas características P. martinezi, na chave de Martins (1999), reune-se com P. piruatinga Martins, 1997 e P. crassicornis (Martins, 1981) sinônima de P.tristis (Blanchard, 1843). 
Pantomallus martinezi distingue-se de P. tristis: pelo colorido geral avermelhado e menos alaranjado; pubescência abundante e densa; escapo esbelto; lados do protórax com tubérculos látero-anteriores e central não-enegrecidos; tubérculos dorsais do pronoto com coloração preta restrita ao tubérculo; pontuação dos élitros nítida e menos áspera; pares de manchas ebúrneas dos élitros com tamanhos nitidamente diferentes; extremidades elitrais apenas projetadas no ângulo externo.

Pantomallus martinezi difere de $P$. piruatinga (comparação entre fêmeas): flagelômeros basais com franja interna de pêlos separados; pubescência protorácica densa; espinho lateral do protórax curto; manchas ebúrneas dos élitros alongadas e com distribuição levemente diferente; ápice dos élitros com espinho curto no ângulo marginal; lado inferior do corpo, principalmente esternos torácicos, com pubescência longa.

\section{Eburodacrys granipennis Gounelle, 1909}

Eburodacrys granipennis Gounelle, 1909:629; Monné, 1993:39 (cat.); Martins, 1999:354, fig. 241.

Eburodacrys granipennis foi originalmente descrita do Brasil, Goiás, mas sua distribuição, já foi ampliada para o Mato Grosso (NAPP \& MArTins, 1980), e significativamente expandida por MarTins (1999) para Trinidad y Tobago, Colômbia (Magdalena), Peru, Brasil (Amazonas) e Bolívia.

Material examinado. COLÔMBIA, Meta: La Macarena (Caño Cristales), ơ, 30.II.1994, G. Mendoza col. (GMIG).

\section{Eburodacrys havanensis Chevrolat, 1862}

Eburodacrys havanensis Chevrolat, 1862:267; Monné, 1993:39 (cat.); Martins, 1999:306, fig.182.

Originalmente descrita de Cuba, E. havanensis está citada para as três Américas, inclusive para a Colômbia: Tolima e Antioquia (MARTINS, 1999).

Material examinado. COLÔMBIA, Quindío: Montenegro (4³4'1"N, 7545’12"W, 1333 m), ९, 5.V.1999, R. Gómez col. (UNAB).

\section{Eburodacrys moruna Martins, 1997}

Eburodacrys moruna MaRTins, 1997:66, fig. 4; 1999:309, fig. 184.

Esta espécie só é conhecida da Província de Magadalena: Santa Marta, Bonda e Don Amo.

Material examinado. COLÔMBIA, Magdalena: PNN (Parque Nacional Natural) Tayrona Zaino $\left(11^{\circ} 20^{\prime} \mathrm{N}, 74^{\circ} 02^{\prime} \mathrm{W}, 50 \mathrm{~m}\right), \sigma^{\circ}, 3-22 . X I .2000$, R. Henriquez col., malaise (IAHC).

\section{Eburodacrys nemorivaga Gounelle, 1909}

Eburodacrys nemorivaga Gounelle,1909:623; Monné, 1993:41 (cat.); Martins, 1999:299, fig. 178.

Eburodacrys nemorivaga é largamente distribuída na América do Sul e MARTINS

Iheringia, Sér. Zool., Porto Alegre, 92(4):5-10, 30 de dezembro 2002 
(1999) mencionou-a para a Venezuela (Sucre), Brasil (Piauí, Goiás, Minas Gerais e São Paulo) e Paraguai (Concepción). É assinalada para a Colômbia pela primeira vez.

Material examinado. COLÔMBIA, Cundinamarca: Girardot $\left(4^{\circ} 18^{\prime} 18^{\prime \prime} \mathrm{N}, 74^{\circ} 48^{\prime} 06^{\prime \prime} \mathrm{W}, 281\right.$ m), P, 1.X.1994, Zambrano col. "tarde arbusto" (MZSP). Tolima: Cumen de Apicalá (Finca La Ponderosa, 409’00"N, 7548’37"W, 328 m), ', 23.X.1998, H. Parada col. (UNAB).

\section{Eburodacrys pilicornis Fisher, 1944}

Eburodacrys pilicornis FISHeR, 1944:5; MonNÉ,1993:42 (cat.); MARTins, 1999:330, fig. 206.

Eburodacrys pilicornis foi originalmente descrita da Venezuela e citada para diversos estados daquele país (ZaJCIw, 1970; MARTINs, 1999), mas agora é assinalada para a Colômbia.

Material examinado. COLÔMBIA, Santander: Barichara (6³8'20"N, 73¹3' 38"W, 1294 m), O', 30.III.1999, J. Afanador \& J. Sanchez col. (UNAB).

\section{Beraba inermis sp. nov.}

(Fig. 2)

o. Colorido geral alaranjado ou vermelho-alaranjado. Tubérculos pronotais, pretos. Espinhos dos fêmures castanhos ou concolores. Cada élitro com três manchas ebúrneas (fig. 2): uma na base, oval, convexa e seguida por curta região acastanhada; duas centrais, subcontíguas, a interna subigual em comprimento à mancha basal e situada ao nível do meio da externa com metade do seu comprimento; ambas precedidas e seguidas por pequenas áreas acastanhadas. Lobos oculares superiores com 4 fileiras de omatídios. Tubérculos anteníferos agudos. Antenas atingem o ápice elitral no meio do antenômero VII ou na extremidade do VI. Escapo com a metade basal profundamente sulcada. Tubérculo látero-anterior do protórax apenas indicado. Espinho dos lados do protórax curto. Pronoto com rugas irregulares em quase toda a superfície. Mesosterno sem tubérculo. Élitros com pontos pilíferos elevados, granulares, principalmente ao lado da sutura e abundantemente pontuados na metade anterior. Extremidades elitrais truncadas com espinho sutural curto.

Dimensões, em mm. Comprimento total, 18,4-20,4; protórax: comprimento 3,6-3,8; maior largura, 4,2-4,3; comprimento do élitro, 13,3-14,7; largura umeral, 4,9-5,1.

Material-tipo. COLÔMBIA, Cundinamarca: Silvania $\left(4^{\circ} 24^{\prime} 21^{\prime \prime} \mathrm{N}, 7^{\circ} 23^{\prime} 24^{\prime \prime} \mathrm{W}, 1470 \mathrm{~m}\right)$, holótipo $\sigma^{\circ}, 3 . X .1976$, S. Fuentes col. (UNAB); Fusagasugá $\left(4^{\circ} 20^{\prime} 49^{\prime \prime N}, 74^{\circ} 21^{\prime} 53^{\prime \prime} \mathrm{W}, 1731 \mathrm{~m}\right)$, parátipo o', 5.XI.1987, G. Alvarez col. (MZSP).

Discussão. Espécies de Beraba Martins,1997 não apresentam sulco no lado dorsal do escapo e têm espinho no lado externo das extremidades elitrais. Em $B$. inermis o escapo é sulcado na base e os ápices dos élitros são desarmados no lado externo. Além disso, $B$. inermis distingue-se de todas as outras espécies de Beraba pelo aspecto das manchas ebúrneas centrais dos élitros: a externa tem o dobro do comprimento da interna e ultrapassaa tanto na frente como atrás e pela presença de grânulos esparsos ao longo da sutura.

Agradecimentos. A Antonio Santos Silva (MZSP) pela execução das fotografias. O material pertencente ao IHAC foi colecionado com o apoio de NSF, DEB 9972024 a M. Sharkey e B. Brown. 


\section{REFERÊNCIAS BIBLIOGRÁFICAS}

Aurivillius, C. 1912. Coleopterorum Catalogus, pars 39, Cerambycinae. Berlin, W. Junk. 574 p. Bates, H. W. 1870. Contributions to an insect fauna of the Amazon Valley. Trans. ent. Soc. London, London, 1870:243-335.

Buquet, J. B. L. 1844. In: Guérin-Méneville, F. E. Iconographie du régne animal de G. Cuvier. Insectes. Paris, Baillière, v.7, IV+5-575p.

Chevrolat, L. A. 1862. Coléoptères de l'Ille de Cuba. Notes, synonymies et descriptions d'espèces nouvelles. Annls Soc. ent. Fr., Paris, (4)2:245-280.

FISHER, W. S. 1944. Cerambycidae of Caripito, Venezuela. Zoologica, New York, 29:3-12.

Gounelle, E. 1909. Liste de cérambycides de la région de Jatahy, État de Goiaz, Brésil. Annls Soc. ent. Fr., Paris, 77:587-688.

Lacordaire, J. T. 1869. Genera de Coléoptères... Paris, Roret. v.8, 552p.

Martínez, C. 2000. Escarabajos longicórnios (Coleoptera: Cerambycidae) de Colômbia. Biota Colombiana, Bogotá, 1(1):76-105.

Martins, U. R. 1997. Contribuições para uma revisão das espécies sul-americanas da tribo Eburiini (Coleoptera, Cerambycidae). Revta bras. Ent., São Paulo, 41:57-83.

1999. Cerambycidae sul-americanos (Coleoptera). São Paulo, Sociedade Brasileira de Entomologia. v.3, VI+418p.

Monné, M. A. 1993. Catalogue of the Cerambycidae (Coleoptera) of the western hemisphere. Part II. São Paulo, Sociedade Brasileira de Entomologia. 77p.

2001. Catalogue of the neotropical Cerambycidae (Coleoptera) with known host plant. Part I: Subfamily Cerambycidae, tribes Achrysonini to Elaphidiini. Publ. avuls Mus. nac. Rio de J., Rio de Janeiro, (88):3-108.

NApp, D. S. \& Martins, U. R. 1980. Sinonímias, descrições e chaves para as espécies de Eburodacrys White, 1853. (Coleoptera, Cerambycidae). Papéis Avuls Zool., São Paulo, 33:77-97.

Waterhouse, C. O. 1880. New Cerambycidae from the Ecuador. Ann. Mag. nat. Hist., London, (5)5:485-488.

ZaJciw, D. 1970. Contribuição para o estudo de Eburodacrys triocelata Stal (Col., Cerambycidae, Cerambycinae). Revta bras. Biol., Rio de Janeiro, 30:543-546.

Zanella, F. C. V.; Oliveira, M. L. DE \& Gaglione, M. C. 2000. Standardizing lists of locality data for specimens in systematics and biogeography studies of new world taxa. Biogeographica, Paris, 76: $145-160$.

Recebido em 25.01.2002; aceito em 05.02.2002.

Iheringia, Sér. Zool., Porto Alegre, 92(4):5-10, 30 de dezembro 2002 